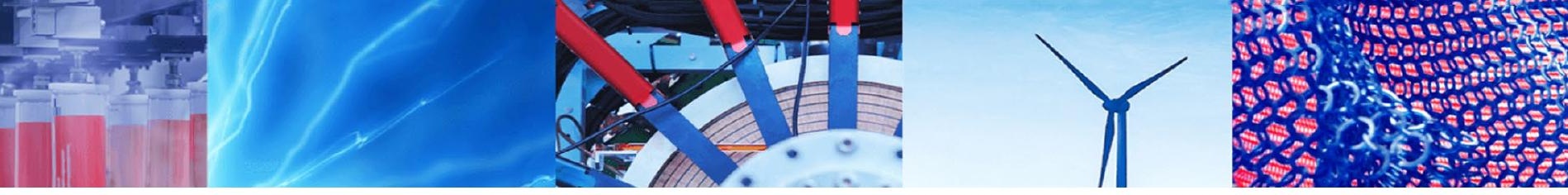

Review Paper

\title{
Methods to optimize energy consumption in Conarc furnaces
}

\author{
Aashay Wanjari ${ }^{1}$ (D) \\ Received: 1 September 2021 / Accepted: 28 October 2021 \\ Published online: 17 November 2021 \\ (c) The Author(s) 2021 OPEN
}

\begin{abstract}
Over the past few decades, steelmaking has reached its zenith in terms of annual productivity, and relevant processes have been developed over time to produce steel with maximum efficiency in a shorter time. One of the prominent steelmaking practices used extensively in contemporary industries is the Conarc Steelmaking Practice, which involves the use of electrical and chemical Energy to carry out melting and decarburization in respective shells. This article reviews the factors that affect the energy consumption in Conarc furnaces and provides insight into the technologies developed to alleviate energy consumption and make the steelmaking process optimal in terms of energy consumption and requirement. This article also accentuates relevant systems and melting practices for the raw materials, which can be utilized in the Conarc Steelmaking practice to make the entire process less energy-intensive. Oxygen-enhanced combustion and thermophotovoltaic systems can alleviate energy consumption substantially while maintaining steel quality at the same time, as discussed in the paper. Additionally, some mathematical models have been discussed that facilitate in formulating an energy optimal and financial steelmaking process.
\end{abstract}

Keywords Steelmaking · Conarc furnace · Energy consumption · Energy optimization · Energy conservation and management in steelmaking

\section{Introduction}

With the advent of several steelmaking technologies and processes in the past century, it has become paramount for industries to select the steelmaking processes that are efficient and optimized for maximum profit in terms of finance and resource use. Steelmaking processes like the top-blown basic oxygen furnace (BOF) and electric arc furnace (EAF) have significantly influenced steel production over the last couple of decades and are being used extensively in the contemporary era. However, these steelmaking processes have their limitations and shortcomings in terms of energy consumption and process efficiency, and this has sparked a need for a more efficient steelmaking process that can also be used with a wide array of raw materials.

One such steelmaking process is the Conarc Steelmaking Process, which has been used in several steel industries for the past few years due to its numerous advantages and broad applicability. The main reason for the development of the Conarc Process was to employ the benefits of both the BOF process and the EAF process under a single apparatus [9]. The name "CONARC" comes from combining the CONventional top-blown BOF process and the electric ARC process. The main principle of this process lies in applying the steelmaking principles that are being used in both the BOF and EAF processes. Furthermore, this process aims to use hot metal extensively in the EAF part, minimize energy wastage, and maximize productivity. The BOF process in

Aashay Wanjari, aashaywanjari@gmail.com | 'Department of MME, Visvesvaraya National Institute of Technology, South Ambazari Road, Nagpur 440010, India.

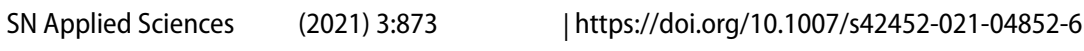


Conarc Steelmaking is primarily employed for decarburization of the steel melt, while the EAF process is employed for melting the raw materials.

The basic set-up for the Conarc furnace consists of two similar furnace shells that are primarily refractory-lined, a rotating electrode structure containing one set of electrodes that serve both the shells, one electric supply in the form of a transformer for both the shells and one rotating water-cooled top oxygen lance system. It is important to note that these two shells can be used interchangeably; however, only one shell can operate either as a BOF shell or as an EAF shell at a particular instant, and hence, the second shell must operate in the other mode. Thus, decarburization of the melt is carried out in one shell, while electric melting of the raw materials is carried out in the other shell at a given instant [9].

\section{Procedure and steps followed in the Conarc process}

The procedure of steelmaking via Conarc Process consists of the following steps:

- Charging the liquid iron via a torpedo into a liquid heel.

- Oxygen lancing of the melt to carry out decarburization and to remove other detrimental impurities.

- Lowering the electrodes to carry out the melting process (arcing).

- Increasing the temperature of the liquid bath to the required value.

- Tapping out the liquid melt.

From the steps mentioned above, it can be concluded that the Conarc Steelmaking process is divided into two stages: the Converter Stage and the EAF Stage. In the first stage, which is the Converter Stage, the decarburization of liquid iron is carried out by blowing oxygen into the liquid melt through the top. In this stage, the carbon, silicon, manganese, and phosphorous content of the bath is reduced, as these are the unwanted elements present in the steel melt. The chemical reactions associated with removing these impurities are exothermic, meaning that the reactions are accompanied by the generation of a large amount of heat. Cold materials like scrap or DRI are added to the furnace to utilize this energy and avoid overheating the bath. In the second stage, the EAF Stage, the electric energy is utilized to melt the solid charge and superheating the bath to the tapping temperature. During this stage, the remaining solid charge material like scrap or DRI is charged into the liquid bath to attain the required tapping weight of the batch (heat). The temperature of the bath is then increased to the required value, and after the required temperature is attained, arcing is concluded, and deslagging is carried out before tapping the melt into a ladle.

The process of charging in the Conarc Steelmaking is carried out either via the roof or via launder. The charging method plays a vital role in altering the energy consumption of the Conarc Process and the subsequent processes. Owing to the specific advantages and disadvantages of the charging methods, launder charging is practiced extensively in steel industries.

Charging through the roof: The scrap is initially melted in the EAF shell with a closed roof by arcing. After completion of melting, the roof is opened, and hot metal is poured into a vessel. The significant advantage of this process is that the temperature drop of the liquid melt is minimized; however, the melting of scrap is interrupted continuously as the roof of the shell is opened and closed accordingly. Moreover, high amounts of radiation losses are observed when the roof is opened, making roof charging unconventional in industries.

Charging using launder: The scrap is first charged, accompanied by closing the roof and immersion of electrodes to initiate melting. After a liquid melt is formed, launder is inserted through the shell's door, and the hot metal is poured at a specific rate into the vessel while scrap melting continues without any disruption. Hence, the advantages of using launder charging are uninterrupted scrap melting, no heat losses by radiation, and no increase in the tap-to- tap time of the batch.

The Conarc Process also employs extensive use of DRI as one of its raw materials. The DRI contains low amounts of tramps or residual elements like copper, tin, arsenic, and zinc, and this implies that DRI can be blended suitably with scrap containing such impurities to reduce their presence in the final steel product. Furthermore, the carbon content of the DRI can be controlled as per the requirements of a specific steelmaking practice. When DRI is to be melted under oxidizing conditions, the carbon content is as high as about $2 \%$. The metallic content of the iron ore in the DRI denotes the metallization of the DRI and is measured in percentage. Generally, around 92\% Metallization [2] is considered industrially viable, and this is achieved if gaseous hydrocarbons are used for its production (Figs. 1, 2, 3, 4, 5).

\section{Factors affecting energy consumption and subsequent methods to optimize energy consumption}

Despite adopting the EAF practice in the Conarc furnace, the debate regarding the type of energy did not stop as there were constant disputes regarding using either chemical or electrical energy to achieve an economic 


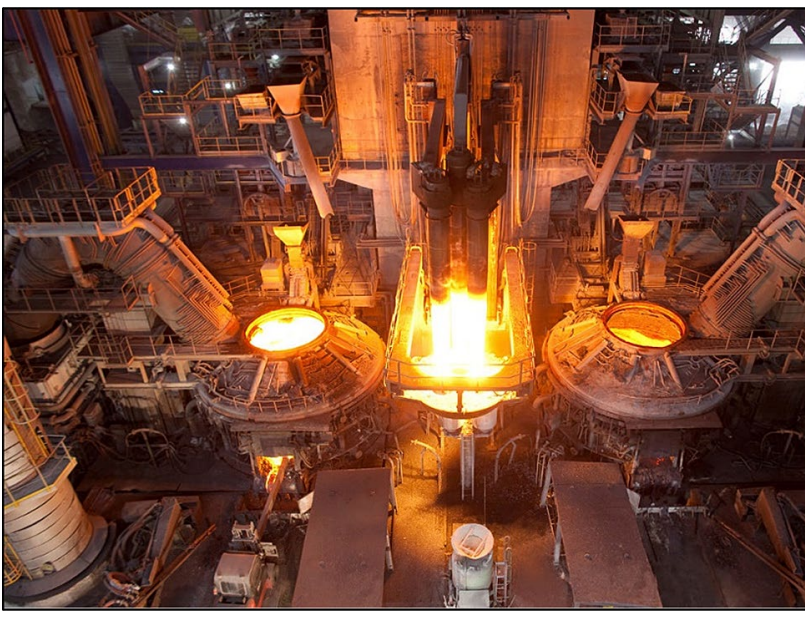

Fig. 1 Conarc plant [9]

steelmaking process. Various factors that contribute to this debate are the financial requirements of the industry and the restrictions imposed towards the use of either energy type [27]. Hence, as per the analysis [3], which critically analysed the energy efficiency for carrying out various functions in steelmaking, it was observed that most of the supplied energy is required for heating the raw materials, and only a tiny amount of the energy is utilized for melting. Furthermore, electrical energy is preferably used for overheating the charge, while chemical energy is used for heating and melting [28].

From Fig. 6 , it is evident that most of the supplied energy is utilized for three primary functions:

- Heating the solid scrap to its melting point.
- Melting the solid scrap.

- Superheating the bath.

Thus, nearly $71 \%$ of the total energy is required just for heating the scrap, which is the first step of any conventional steelmaking process. Nearly $19 \%$ is required to melt the solid charge, and only $10 \%$ is required for superheating the bath.

Since an enormous amount of surface area is available in solid charge, the heating efficiency of the fossil fuels (chemical energy) in heating the charge is higher than the one observed by using the electric arc (electric energy). On the other hand, heating of the molten bath by an electric arc is more efficient than fossil fuels because of the absence of sufficient surface area, which is necessary for efficient heat transfer. Hence, the specific surface area of the charge plays a vital role in deciding which mode of energy supply, whether chemical or electrical, would be more efficient, and hence, the energy requirements would vary accordingly [30, 31].

\subsection{Type of fuel used and environmental concerns}

The contemporary electric arc furnaces involve fossil fuel energy for melting the solid charge $[3,20]$, and once the solid charge is molten, the energy source is switched over to the electric arc since molten baths heat more efficiently by electric arc due to lesser surface area. However, since non-renewable resources like fossil fuels have adverse effects on the climate, the modern emphasis is on reducing the overall emission rates. Greenhouse gases (GHG), which are emitted from fossil fuels, contribute heavily to climate change, and as a result, there is a necessity to limit
Fig. 2 Exothermic oxidation reactions and energy released [4]

Exothermic oxidation reactions and energy released during steel melt refining.

Energy released

$$
\begin{aligned}
& \text { Reactions in melt } \\
& \mathrm{Si}+\mathrm{O}_{2} \rightarrow \mathrm{SiO}_{2} \\
& \mathrm{Mn}+0.5 \mathrm{O}_{2} \rightarrow \mathrm{MnO} \\
& 2 \mathrm{Cr}+1.5 \mathrm{O}_{2} \rightarrow \mathrm{Cr}_{2} \mathrm{O}_{3} \\
& 2 \mathrm{Fe}+1.5 \mathrm{O}_{2} \rightarrow \mathrm{Fe}_{2} \mathrm{O}_{3} \\
& \mathrm{Fe}+0.5 \mathrm{O}_{2} \rightarrow \mathrm{FeO} \\
& \mathrm{C}+0.5 \mathrm{O}_{2} \rightarrow \mathrm{CO} \\
& 2 \mathrm{Al}+1.5 \mathrm{O}_{2} \rightarrow \mathrm{Al}_{2} \mathrm{O}_{3} \\
& \mathrm{Mo}+\mathrm{O}_{2} \rightarrow \mathrm{MoO}_{2} \\
& \mathrm{~S}+\mathrm{O}_{2} \rightarrow \mathrm{SO}_{2} \\
& 2 \mathrm{P}+2.5 \mathrm{O}_{2} \rightarrow \mathrm{P}_{2} \mathrm{O}_{5}
\end{aligned}
$$

$3.05 \mathrm{kWh} / \mathrm{kg}_{\mathrm{cr}}$

$2.55 \mathrm{kWh} / \mathrm{kg}_{\mathrm{C}}$

$5.29 \mathrm{kWh} / \mathrm{kg}_{\text {Al }}$

$2.75 \mathrm{kWh} / \mathrm{kg}_{\mathrm{s}}$

$5.54 \mathrm{kWh} / \mathrm{kg}_{\mathrm{P}}$

Reactions in gas phase

$$
\begin{aligned}
& \mathrm{C}+\mathrm{O}_{2} \rightarrow \mathrm{CO}_{2} \\
& \mathrm{CO}+0.5 \mathrm{O}_{2} \rightarrow \mathrm{CO}_{2} \\
& \mathrm{H}_{2}+0.5 \mathrm{O}_{2} \rightarrow \mathrm{H}_{2} \mathrm{O}
\end{aligned}
$$

$8.94 \mathrm{kWh} / \mathrm{kg}_{\mathrm{si}}$

$1.93 \mathrm{kWh} / \mathrm{kg}_{\mathrm{Mn}}$

$2.05 \mathrm{kWh} / \mathrm{kg}_{\mathrm{Fe}}$

$1.32 \mathrm{kWh} / \mathrm{kg}_{\mathrm{Fe}}$

$1.70 \mathrm{kWh} / \mathrm{kg}_{\mathrm{Mo}}$

$11.2 \mathrm{kWh} / \mathrm{m}_{\mathrm{O}}^{3}$ $9.48 \mathrm{kWh} / \mathrm{m}_{\mathrm{O}_{2}}^{3}$ $9.42 \mathrm{kWh} / \mathrm{m}_{0}^{3}$ $6.80 \mathrm{kWh} / \mathrm{m}_{\mathrm{O}}^{3}$ $6.58 \mathrm{kWh} / \mathrm{m}_{0}^{3}$ $2.73 \mathrm{kWh} / \mathrm{m}_{0}^{3}$ $13.84 \mathrm{kWh} / \mathrm{m}_{0}^{3}$ $7.29 \mathrm{kWh} / \mathrm{m}_{\mathrm{O}_{2}}^{3}$ $3.94 \mathrm{kWh} / \mathrm{m}_{0}^{3}$ $8.58 \mathrm{kWh} / \mathrm{m}_{0}^{3}$,

$9.10 \mathrm{kWh} / \mathrm{kg}_{\mathrm{c}}$
$4.88 \mathrm{kWh} / \mathrm{m}_{0}^{3}$ $7.01 \mathrm{kWh} / \mathrm{m}_{0}^{3}$ $5.99 \mathrm{kWh} / \mathrm{m}_{\mathrm{O}_{2}}^{3}$ 


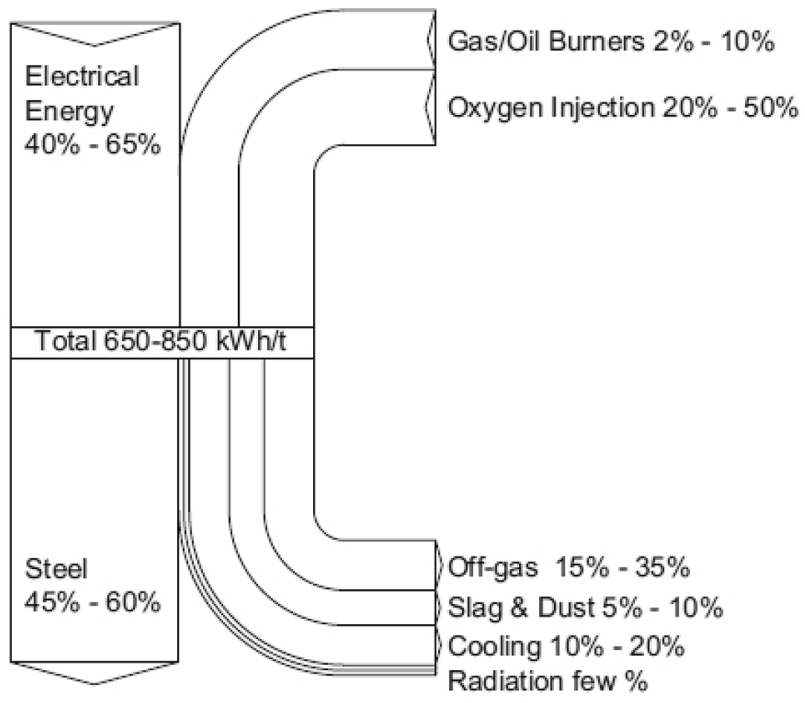

Fig. 3 Energy sources in EAF furnace [1]

their use, especially on an industrial scale. Furthermore, a massive fraction of electrical energy required for operating the furnace is generated by burning coal, another fossil fuel, in power stations. Generally, thermal power plants function around $35-49 \%$ efficiency, and this efficiency is further reduced because of additional 10-12\% transmission losses, which are observed while transporting the power. This power is then converted to thermal energy, which is utilized for steelmaking in the EAFs. Hence, the direct use of fossil fuels in EAF needs to be regulated and optimized.

Thus, it is advantageous to use fossil fuel for steelmaking in an optimal manner directly [3]. It means that the heating of scrap and its melting must be carried out using fossil fuels, and once the charge attains a molten state, subsequent heating of the bath must be carried out using an electric arc. Hence, it is essential to use the appropriate type of fuel for the EAF furnace as it can significantly influence the power requirements of the subsequent processes.

The following graph [4] denotes the specific electrical energy input and specific oxygen and natural gas consumption in EAF steel plants over the years.

The figure mentioned above shows the distribution of greenhouse gas (GHG) sources reductions for the current conventional EAF process [5]. We must use the fuel sources judiciously given the effects that they have on the environment. The use of fossil fuels is promoted for heating; however, fossil fuels have an adverse effect on the environment [22]. Additionally, there are rules and regulations regarding the use of these fuels as imposed by the governments and by the Paris Agreement. Holistically, it must be kept in

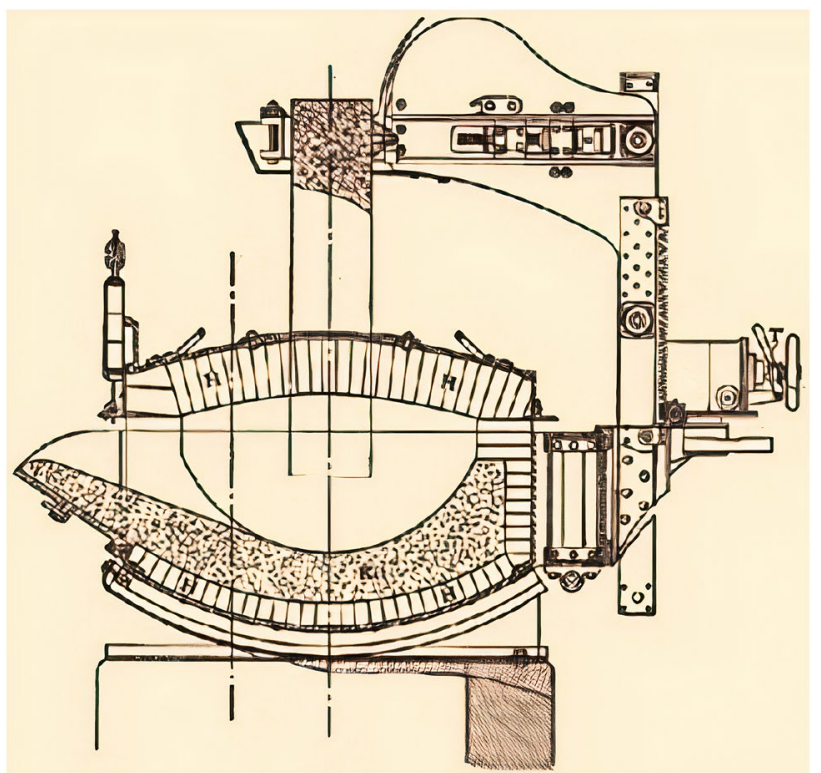

Fig. 4 Roof charging [18]

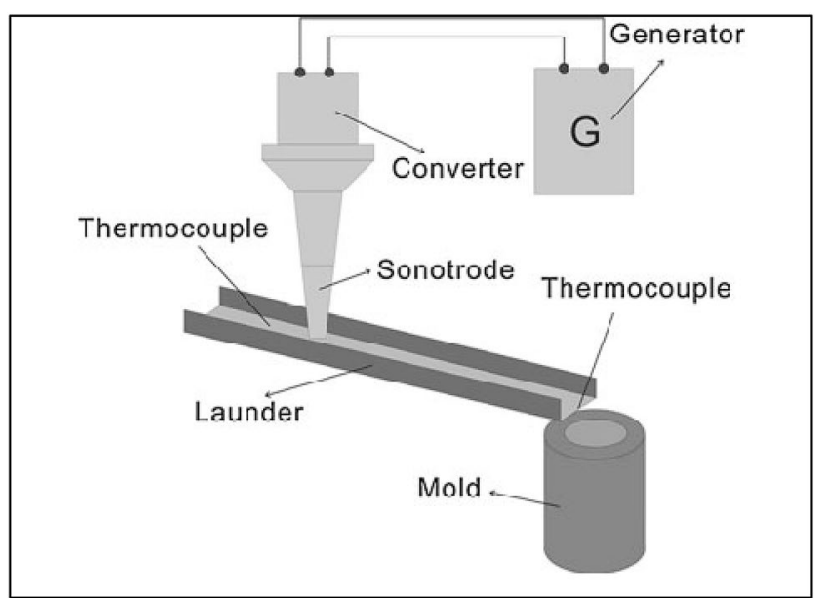

Fig. 5 Launder schematic [20]

mind to switch to the appropriate energy source to abide by the environmental regulations set forth.

\subsection{Type of electric furnace used}

The type of furnace that is being for melting also plays a vital role in affecting the energy consumption of the Conarc furnace. The furnaces are categorized as either alternating current or direct current voltages, each having their pros and cons [26].

The electric arc furnaces in the modern industries use alternating current (AC) majorly. However, direct current furnaces were used extensively in the past, and much 
Fig. 6 Energy use in a steelmaking process [3]
Electrical Energy

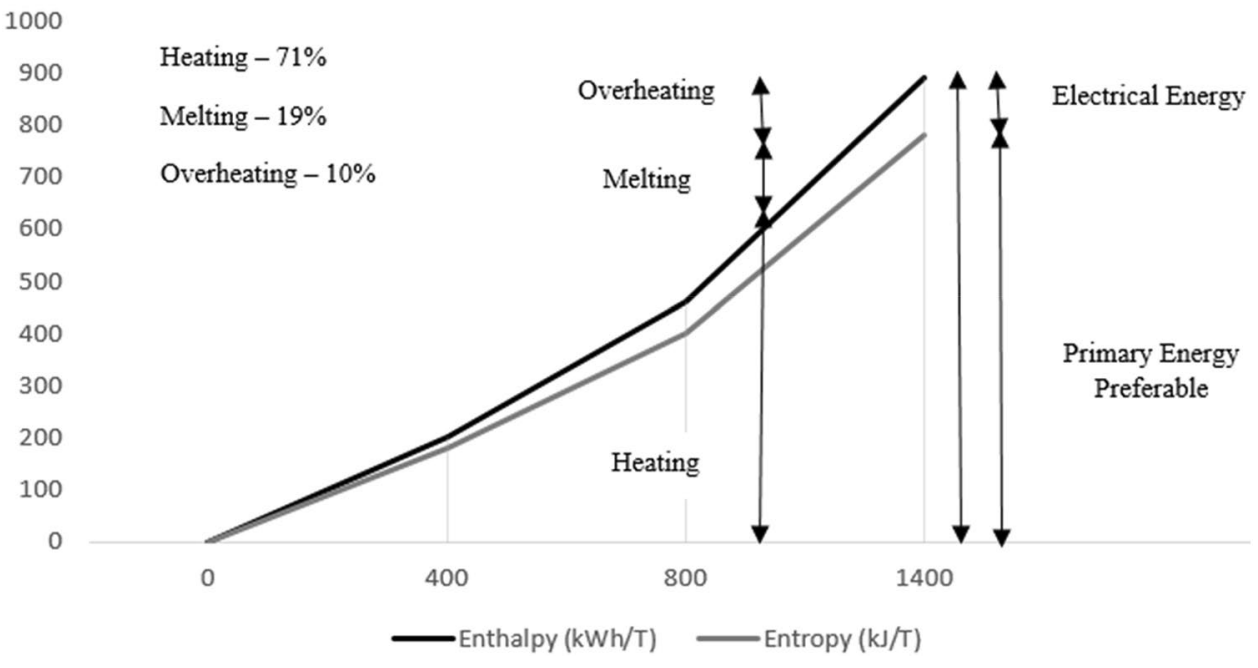

research was oriented towards DC furnaces. The motive for this was several factors like lesser electrode consumption, comparatively less energy consumption and less arc flickering. Arc flickering is a crucial process parameter for electric arc furnaces as maintaining a stable arc during arcing is of paramount importance. A stable arc not only ensures uniform melting but also facilitates a stable melting procedure holistically. DC furnaces have several designs [6], and the two most prominent ones are one electrode and one anode in the furnace bottom and two electrodes with four anodes. Initially, long life for the furnace bottom and refractories were expected, and then, new ideas for DC power conversion were promoted, such as the chopper technology, freewheeling, or split-alpha control to reduce flicker and generate reactive power. Unfortunately, not all the expectations of the DC EAFs were met, and its disadvantages overshadowed the advantages offered by the $D C$ EAF. Although DC EAFs had a lower electrode consumption, the higher specific cost of larger diameter electrodes overshadowed this advantage. Furthermore, some DC EAF anode designs had a comparatively shorter life, and replacing them became an issue for industries as halting the process frequently proved to be more uneconomical. Other DC EAF technologies like chopper technology had higher losses and equipment costs leading to high maintenance costs, which rendered it obsolete in industries.

From Table 1, the differences between the two types of furnaces can be understood based on the experimental data, which Bowman [7] summarized. Based on this data, the applicability of both furnace types is made clear. However, it must be noted that despite the energy and cost abatements offered by the AC furnaces, some of the modern industries still use DC furnaces as they offer lesser arc flickering and are simpler to maintain and operate [7].

\subsection{Charge preheating}

The energy requirements must be decreased or optimized to make a steelmaking process more economical. To achieve this, the enthalpy contained in the exhaust gases that are evolved is used for preheating the charge. Charge preheating is practiced in steelmaking to raise the temperature of the solid charge to a specific value so that the electrical energy that is invested in doing so is alleviated
Table 1 Comparison between AC and DC Furnaces [7]

\begin{tabular}{ll}
\hline AC furnaces & DC furnaces \\
\hline Electrical efficiency: $>90 \%$ & Electrical efficiency: $>90 \%$ \\
Electrical losses: $2.25-2.55 \mathrm{MW}$ & Electrical losses: $2.97-3.57 \mathrm{MW}$ \\
Energy consumption: $>570 \mathrm{kWh} / \mathrm{t}$ & Energy consumption: $\sim 550 \mathrm{kWh} / \mathrm{t}$ \\
Electrode consumption: higher $(1.66 \mathrm{~kg} / \mathrm{t})$ & Electrode consumption: lower $(1.25 \mathrm{~kg} / \mathrm{t})$ \\
Flicker: higher & Flicker: lower \\
Simplicity: complex & Simplicity: easier \\
Maintenance: difficult & Maintenance: easier \\
Magnitude of magnetic fields: low & Magnitude of magnetic fields: high \\
\hline
\end{tabular}


[21]. Moreover, the enthalpy generated from the exhaust gases is also being used to generate thermal power as a by-product. Some alternative processes have been developed in which the charge is melted in a separate furnace, using fossil fuel and exhaust gases, and the liquid steel flows into the EAF for further refining. Such technologies are now commercially available and employ the use of exhaust gases for the same [29].

The most prominent reaction that facilitates the generation of energy during steelmaking is known as the postcombustion of carbon monoxide and is represented by:

$\mathrm{Co}_{(\mathrm{s})}+0.5 \mathrm{O}_{2(\mathrm{~g})}=\mathrm{CO}_{2(\mathrm{~g})}$

According to Fig. 2, the post-combustion reaction produces energy of around $9.10 \mathrm{kWh} / \mathrm{kg}$ of $\mathrm{C}$, and this energy can be utilized for preheating the charge, as $\mathrm{CO} 2$ is an exhaust gas.

CO preheating is an essential aspect of Conarc Steelmaking as the highly exothermic post-combustion reaction serves as an excellent way to preheat the scrap [4], to save energy costs and consumption. CO preheating is practiced in almost all industrial plants that involve EAF shells as the liberated exothermic energy can be utilized efficiently to heat the scrap and mitigate the energy requirements for the same. One of the methods of achieving this is using an oxygen-enhanced combustor (OEC) for scrap preheating.

As per research conducted by Oh, Lee, and Noh [8], one energy-efficient way of carrying out $\mathrm{CO}$ preheating is the air-used combustion method. In recent years, oxygenenhanced or oxygen-enriched combustion (OEC) is being used to increase thermal efficiency. The core concept of this method is preheating the scrap up to $600^{\circ} \mathrm{C}$ with the high-temperature flue gas (about $1200^{\circ} \mathrm{C}$ ). As a secondary thermal energy source into a relatively cold zone, OEC and carbon lancing play an essential role in increasing electric energy savings. This thermochemical method is one of the ways to reduce electricity usage by removing the energy conversion process of fossil fuel energy to electric energy. The OEC process is characterized by a higher flame temperature than that of air-used combustion.

The advantage of using the OEC process is that the hot-burned gas injected from an oxygen-enhanced burner was well stirred in a furnace and heated the scrap preheat zone homogeneously. The volume-averaged temperature in the furnace was predicted at about $1250^{\circ} \mathrm{C}$ in steady-state conditions, which is advantageous as it is the required temperature for scrap preheating in steelmaking and helps in alleviating energy requirements for preheating as the suitable preheat temperature is attained by this process. Additionally, it was observed that with an increase in the oxygen mole fraction in an oxidant, the likelihood for temperature to rise in the furnace rose dramatically. As the thermal input power increased, the typical time for furnace heat-up grew exponentially.

\subsection{Oxygen lancing and process dynamics}

In the Conarc furnace, once the EAF shell was constructed out of water-cooled panels and its height was increased, it facilitated the top lancing of oxygen in the furnace. However, the top blowing always results in emulsion [10] formation during refining, which is deleterious as slopping is undesired during the top blowing of oxygen. Increasing the production rate by increasing the refining rates, which is achieved by increasing the blowing rate and lowering the lance height, results in enormous foaming and consequently rapid slag flush of liquid metal, which causes an even more significant loss of the metallic yield [23]. Moreover, judicious use of top oxygen blowing is necessary to achieve higher yields and avoid slopping, as oxygen blowing requires electrical energy from the source. Hence, we must use the proper lancing technique to utilize the energy efficiently in the Conarc furnace and prevent slopping. Several techniques are available for this purpose; however, an essential technique is using the jet-box process [11, 25] for top blowing, which can result in a considerable amount of energy requirement abatement.

The jet-box is installed on the EAF to enhance productivity by increasing the thermal energy supply to the charge and making the top blowing more dynamic. During the melting of DRI, under arcing conditions, the jet-box is operated at its maximum efficiency. It contributes more dynamism to the boiling steel melt due to the bottom purging and carbon reaction. The practice of bottom purging, which is necessary for slag and metal mixing, contributes its dynamism to the refining operation. These factors collectively make the entire blowing process very dynamic, which is desired in industries as a massive amount of energy is saved because the blowing process is optimized. The use of foamy slag practice during top blowing increases the dynamism in such a manner that the slag flows out of the furnace door at a fast and steady rate, decreasing the tap-to-tap time as a result.

Consequently, this high flushing rate carries a great deal of metal along with it, and the liquid metal flows out of the furnace as a pipe-like stream along with the slag. It reduces the metal yield correspondingly by another $2-6 \%$. Hence, the jet-box process increases the process dynamism significantly, leading to a decrement in the energy requirements for the process of lancing (Figs. 7, 8, 9, 10, 11, 12, 13, 14). 
Fig. 7 Mean specific electrical energy input and specific consumption of oxygen and natural gas in EAF steel plants [4]
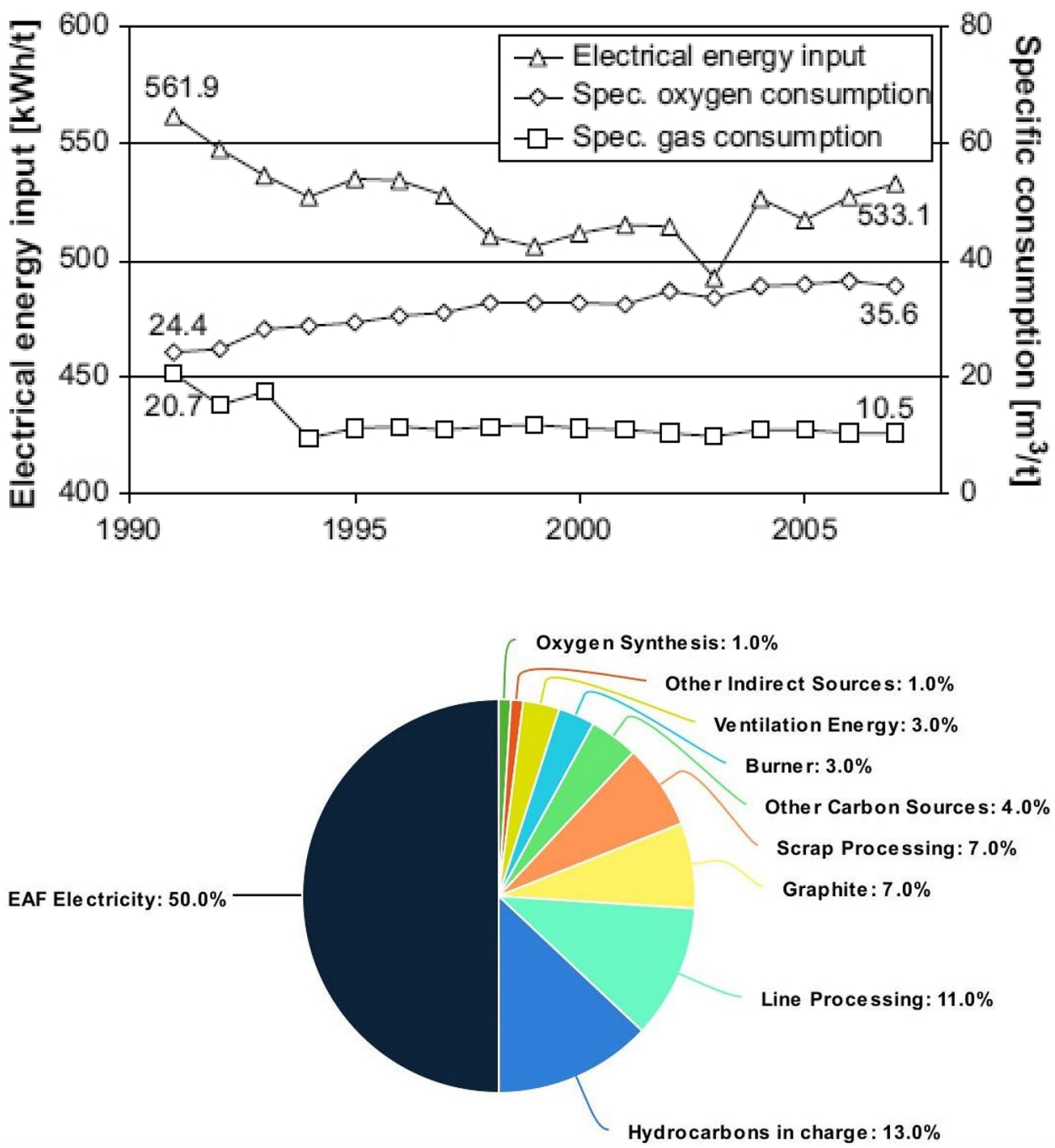

The advantages of the jet-box process can be summarized in Table 2 as follows:

\subsection{DRI melting process and parameters}

The next factor that affects the energy consumption in the Conarc furnace is the DRI melting process and the various process parameters associated with it. The melting of the DRI should be carried out strictly under reducing conditions to alleviate iron loss [3]. If melting under reducing conditions is not feasible, it must be carried out under neutral conditions. However, melting of DRI must not be carried out when arcing is done in the furnace as the atmosphere during this process is oxidizing in nature, and this affects the DRI adversely in terms of iron loss and quality loss, as the oxidizing atmosphere increases the slag volume and contributes to iron loss by mechanical entrapment. As a result, it is recommended to melt the DRI after a pool of liquid iron is formed so that the DRI can be charged into the melt to minimize the furnace oxidization. Hence, the process of melting the DRI must be carried out judiciously as much energy is required for DRI melting.

Furthermore, the DRI variables like \% metallization, \% gangue, and \% carbon affect the energy consumption during the Conarc steelmaking practice. There must be sufficient carbon content in the DRI to balance out the FeO in DRI [19]. Hence, for this, nearly $1 \%$ Carbon content is required to balance $6 \%$ of $\mathrm{FeO}$ content, and this can, in turn, improve the iron yield obtained from DRI melting. Additionally, as silica is inevitably the gangue associated with DRI, basicity of 2.5-3.0 is recommended for the slag to melt efficiently. The appropriate basicity will lead to lower iron oxide loss in the slag and energy savings as well.

The melting process of DRI can be described on a micro level as follows [3]:

- DRI particles get heated when they are under the state of free fall from the hopper until they reach the bath.

- During this fall, the DRI is also partially oxidized. 

trode and bottom anode [6]
Fig. 9 DC EAF with one elec-

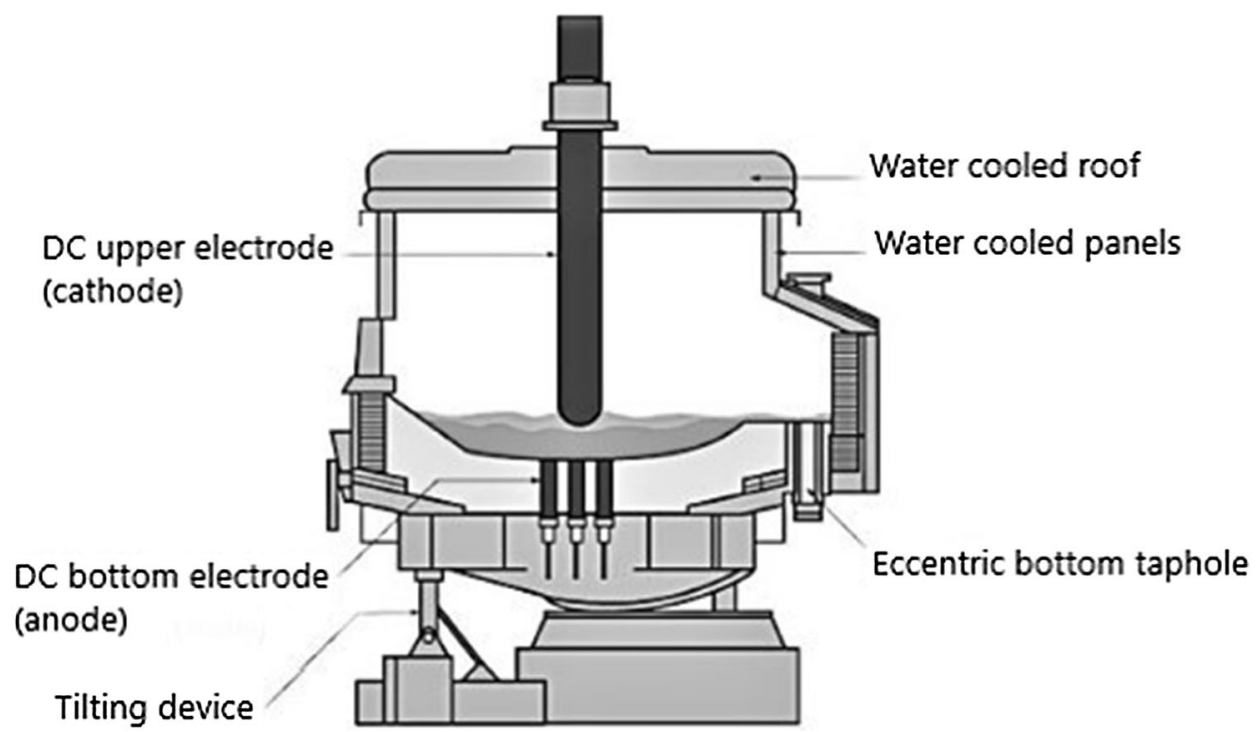

$34.5 \mathrm{kV}$

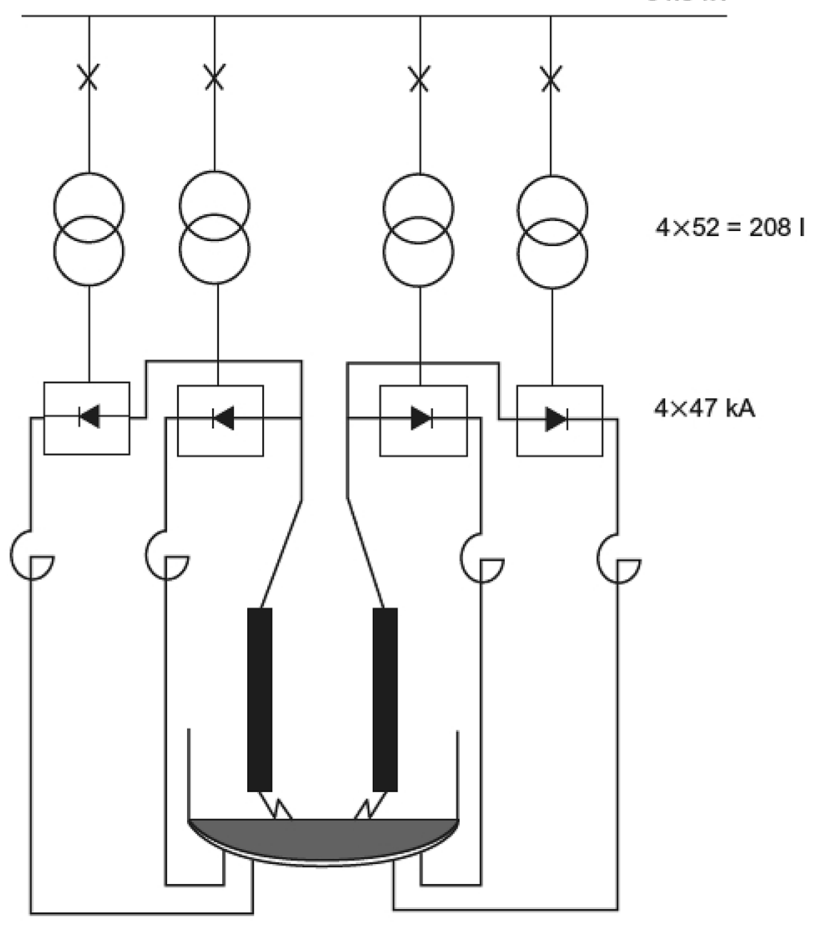

Fig. 10 DC EAF with two electrodes and four bottom anodes [6]

- The DRI particles have a chilling effect on the bath when they come in contact with it.

- The DRI particles get heated with time while in the bath.

- Mass transfer and heating takes place at the Fe(DRI)/ $\mathrm{Fe}$ (melt), $\mathrm{FeO}(\mathrm{DRI}) / \mathrm{Fe}$ (melt), Gangue(DRI)/Fe(melt), $\mathrm{Fe}(\mathrm{DRI}) /$ slag, and Gangue(DRI)/slag interfaces on a micro level.

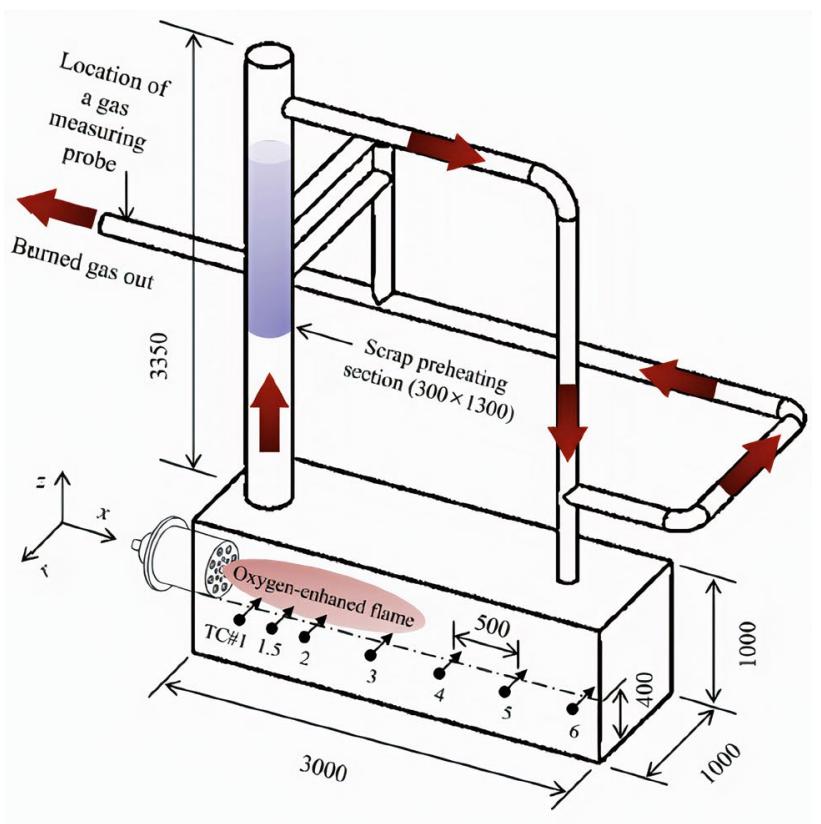

(a)

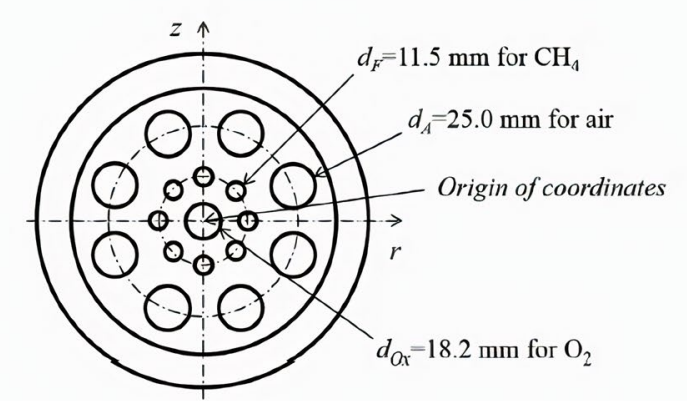

(b)

Fig. 11 Geometry and dimension of a pilot-scale EAF simulator and oxygen-enhanced combustor (unit: $\mathrm{mm}$ ) [8] 


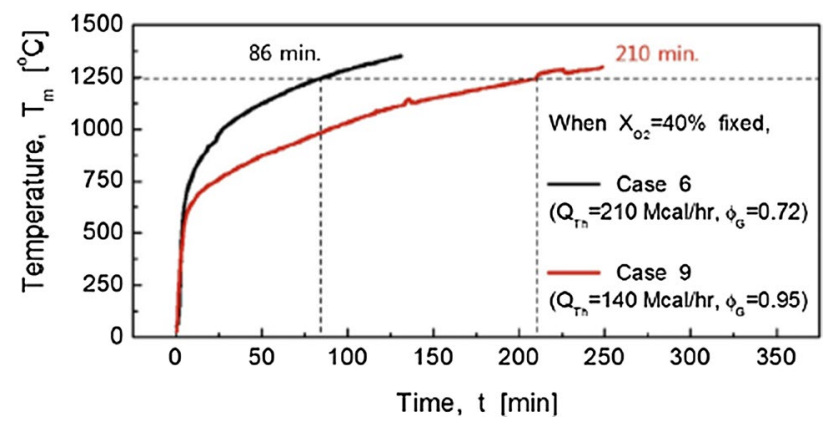

Fig. 12 Comparison of the temperature increase curves between $\mathrm{CH} 4$-air combustion and oxygen-enhanced combustion [8]

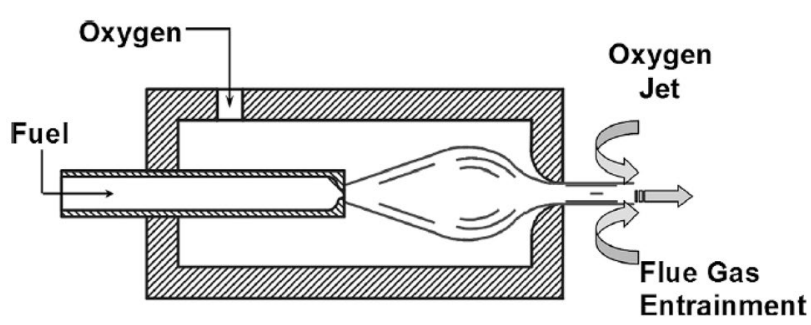

Fig. 13 Oxygen lancing principle [11]

- The rate of the interactions mentioned above decides the rate of dissolution of the DRI in the melt.

- On a macro-level, the DRI particles absorb heat from the melt and dissolve themselves eventually.

- The entire process is time dependent and a mass transport-controlled process, which requires heat for its completion. Hence, the feed rate has to match with the rate of energy input.
Table 2 Jet-box system analysis at ISCOR [12]

\begin{tabular}{ll}
\hline Item & Change \\
\hline Power on time & $-6 \mathrm{~min}$ \\
Oxygen consumption & $+10 \mathrm{Nm}^{3} / \mathrm{t}$ \\
Fuel consumption & $+0.19 \mathrm{GJ} / \mathrm{t}$ \\
Electrode consumption & $-0.25 \mathrm{~kg} / \mathrm{t}$ \\
Electrical energy consumption & $-65 \mathrm{kWh} / \mathrm{t}$ \\
\hline
\end{tabular}

Thus, the feed rate must follow the relation wherein,

Power Input Rate $=$ Thermal Energy Requirements for heating and melting the DRI up to the bath temperature Hence, a correct feed rate must be employed abreast the furnace's total electrical and chemical energy input rate.

A loss of yield is observed otherwise since production pressure in industries hastens this parameter and is often ignored. Furthermore, it is also crucial that most of the oxygen contained in the DRI must get reduced by carbon or silicon at the same rate at which melting is carried out. The DRI particles size also has a decelerating effect on the DRI dissolution rate.

Furthermore, the \% metallization in the DRI should also be optimum to make energy consumption as low as possible [13]. From Fig. 15, it is evident that energy consumption decreases as the \% Metallization increases.

The cost and energy benefits that are obtained by increasing the \% metallization in DRI are shown in Table 3 [14].

Hence, an optimum size of DRI and several other melting parameters is recommended in Conarc practice to obtain maximum efficiency of melting, as the melting process requires energy from the transformer (source) (Fig. 16).

Fig. 14 Fig: Jet-box procedure [12]

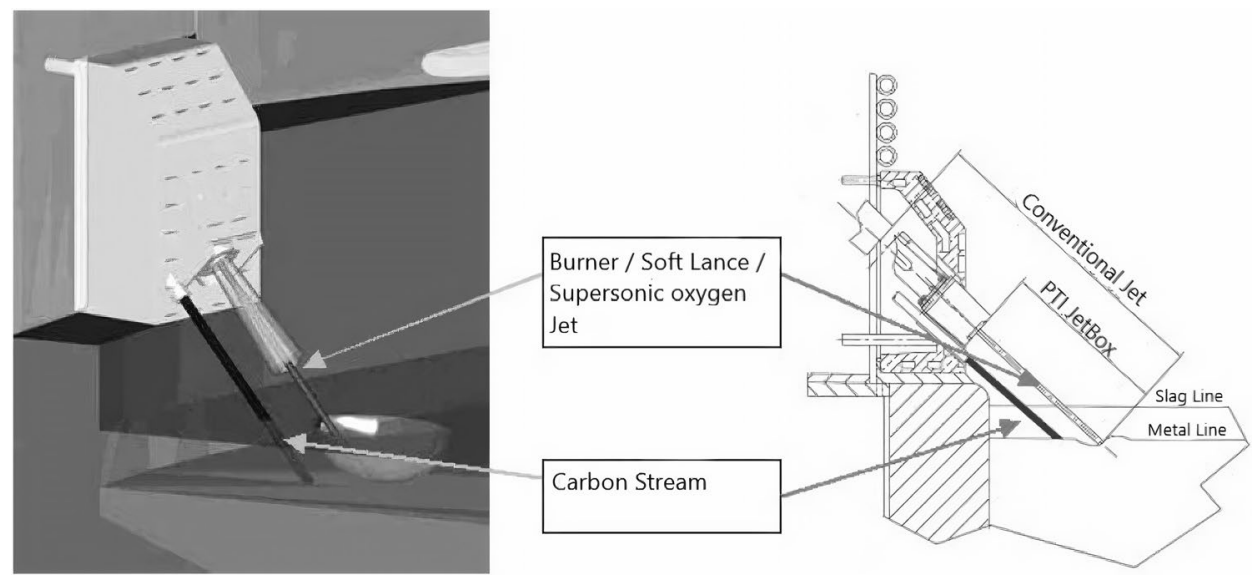


Fig. 15 Energy consumption vs metallization [14]

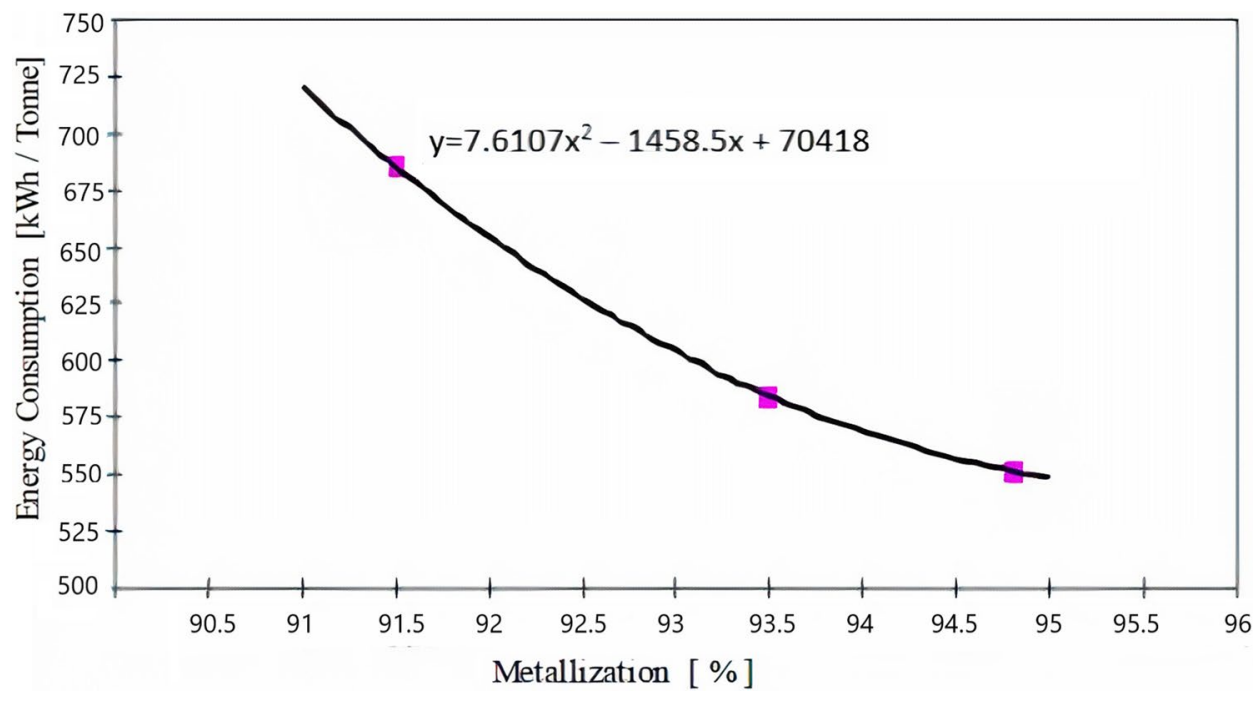

Table 3 Cost and energy savings observed by increasing \% metallization in DRI

\begin{tabular}{ll}
\hline Parameter & Data \\
\hline Electrode consumption & $-0.15 \mathrm{~kg} /$ Tonne \\
Energy consumption & $-25 \mathrm{kWh} /$ Tonne \\
Total cost savings & $-\$ 6.00$ to $-8.09 /$ Tonne \\
\hline
\end{tabular}

\subsection{Radiation losses in the furnace}

Energy loss occurs via radiation from the furnace due to several reasons. The most common reason for radiation losses in the furnace is the charging operation that is being employed. Radiation losses are more when charging is done via the furnace roof. Charging via the launder minimizes the radiation losses; however, energy loss via radiation is inevitable in a steelmaking operation. The inefficiency of the shell wall causes energy loss due to radiation to entrap or contain the heat produced due to the various chemical reactions occurring within the furnace during steelmaking. Loss of this energy is undesirable as it can be used for several purposes in the steelmaking process, like preheating the scrap or heating the raw materials. Over the past years, improvements in energy recovery technology have led to about a $60 \%$ decrease in the energy wastage that is observed due to radiation losses.

The need to utilize or conserve the energy losses is evident from Fig. 17 as the energy losses increase with the on-time of the furnace. Moreover, such amounts of energy wastage are undesirable in industries.

The energy loss in the water-cooled panels used for lining the EAF shell is estimated to be around $306 \mathrm{kWh} / \mathrm{ton}$, equivalent to about $40 \%$ of the input energy. However, energy recovery from these water-cooled panels is not profitable due to its minimal share in the energy flow of the entire process, which is estimated to be around $0.3 \%$. However, some systems facilitate the recovery of this energy, and they have been successful in both theory and practice.

The thermophotovoltaic system (TPV) $[17,24]$ is a highpower density conversion technology, which generates electrical energy from the radiations emitted by a heated
Fig. 16 Illustration of power system in a furnace [15]

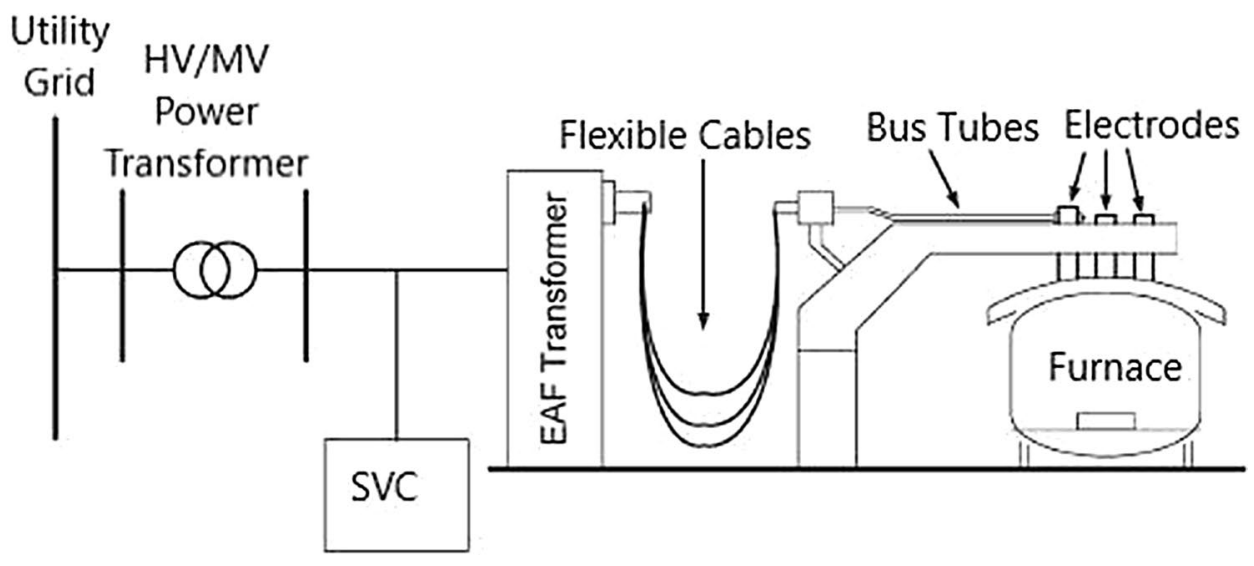




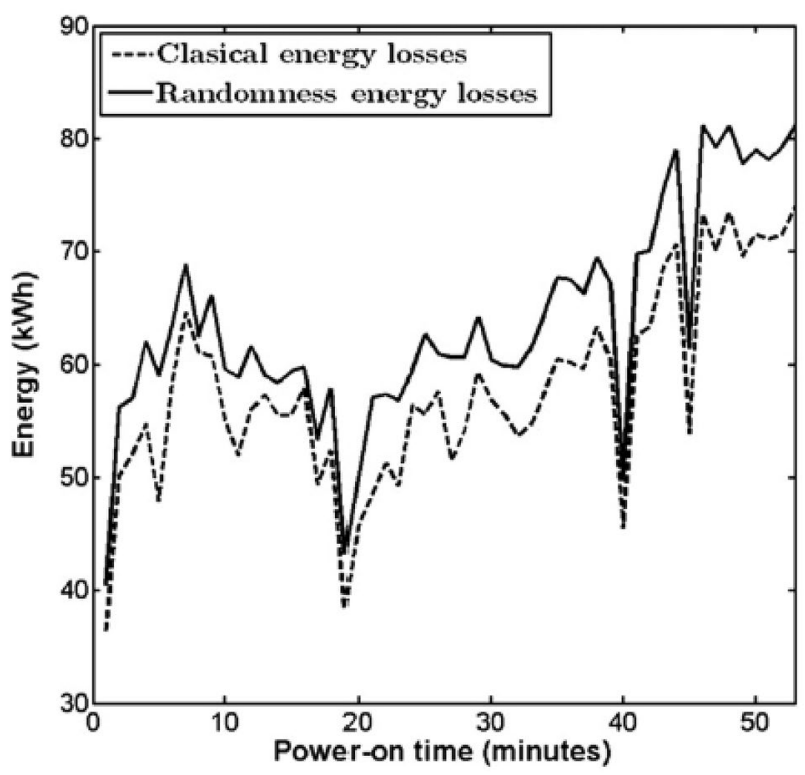

Fig. 17 Estimated energy losses in the EAF shell with the on-time [16]

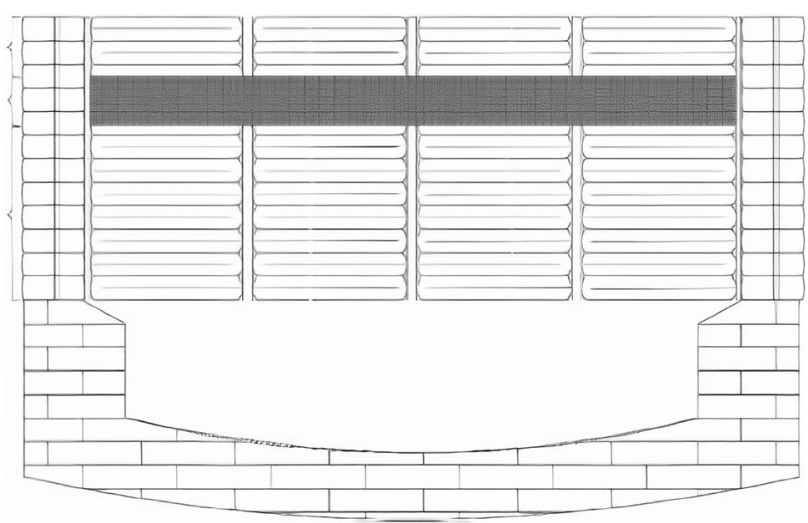

Fig. 18 Schematic representation of an EAF equipped with a TPV system [17] body. This system is promising as it promotes the utilization of a significant amount of the lost energy. In a typical EAF furnace, a part of the upper wall, which is not covered with slag or dust, can be used as a location for placing the TPV system. In addition, due to recovered radiative heat, the TPV also reduces carbon dioxide emissions, as the generated electrical energy can be reused and can replace the electrical energy taken from the power grid. Furthermore, the capacity factor of the TPV system could reach up to $54 \%$ and improves the overall efficiency of the EAF shell up to $0.8 \%$, which is both desirable and profitable (Figs. 18, 19, 20).

\section{Models to optimize energy consumption and costs}

\subsection{Mathematical model for optimizing energy in EAF shell}

In order to formulate a model that accurately accentuates efficient energy management along with producing good quality steel, the following steps are required [32]:

1. Formulating a well-defined model of the objectivethis stage must assuage the aim and objective of the system while being compatible with both of them. This is the primary stage of the model.

2. Formulating an efficiency criteria-by keeping in mind the objective of the required model, proper optimization of the system can be carried out.

3. Formulating options-depending upon the requirements of the system that need to be fulfilled, a specific set of viable options can be selected in order to accomplish the aforementioned objective.

4. Formulating alternative options-to comply with the objective of the system when the formulated approach fails to comply with the objectives under certain circumstances.
Fig. 19 The effect of TPV on overall heat efficiency [17]

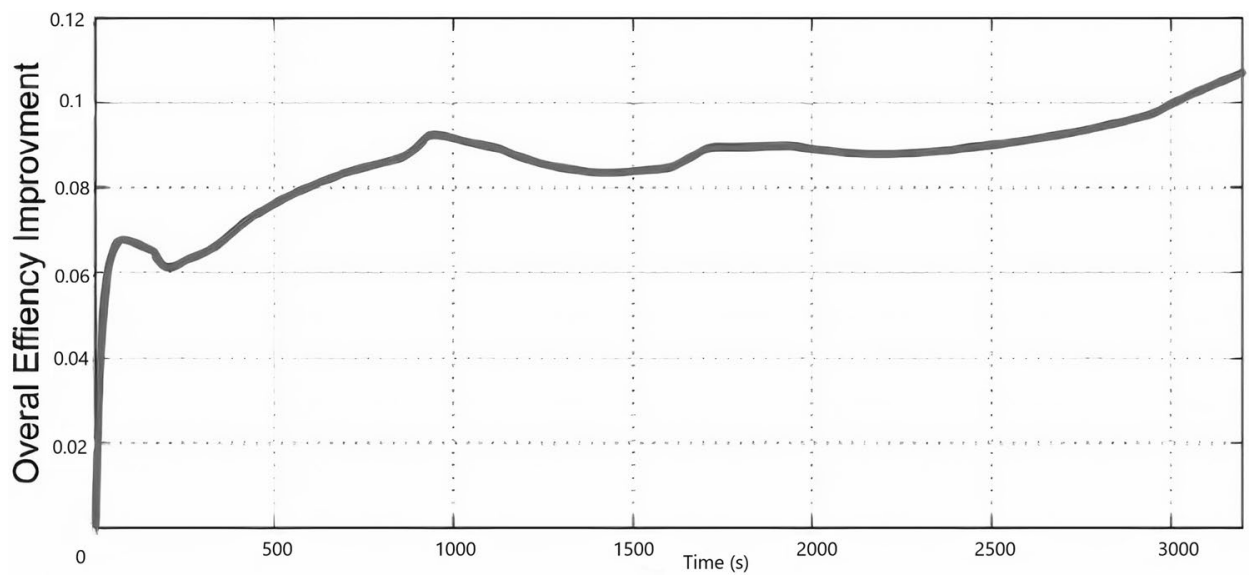

SN Applied Sciences A SPRINGER NATURE journa 
Fig. 20 Optimization control block diagram [34]

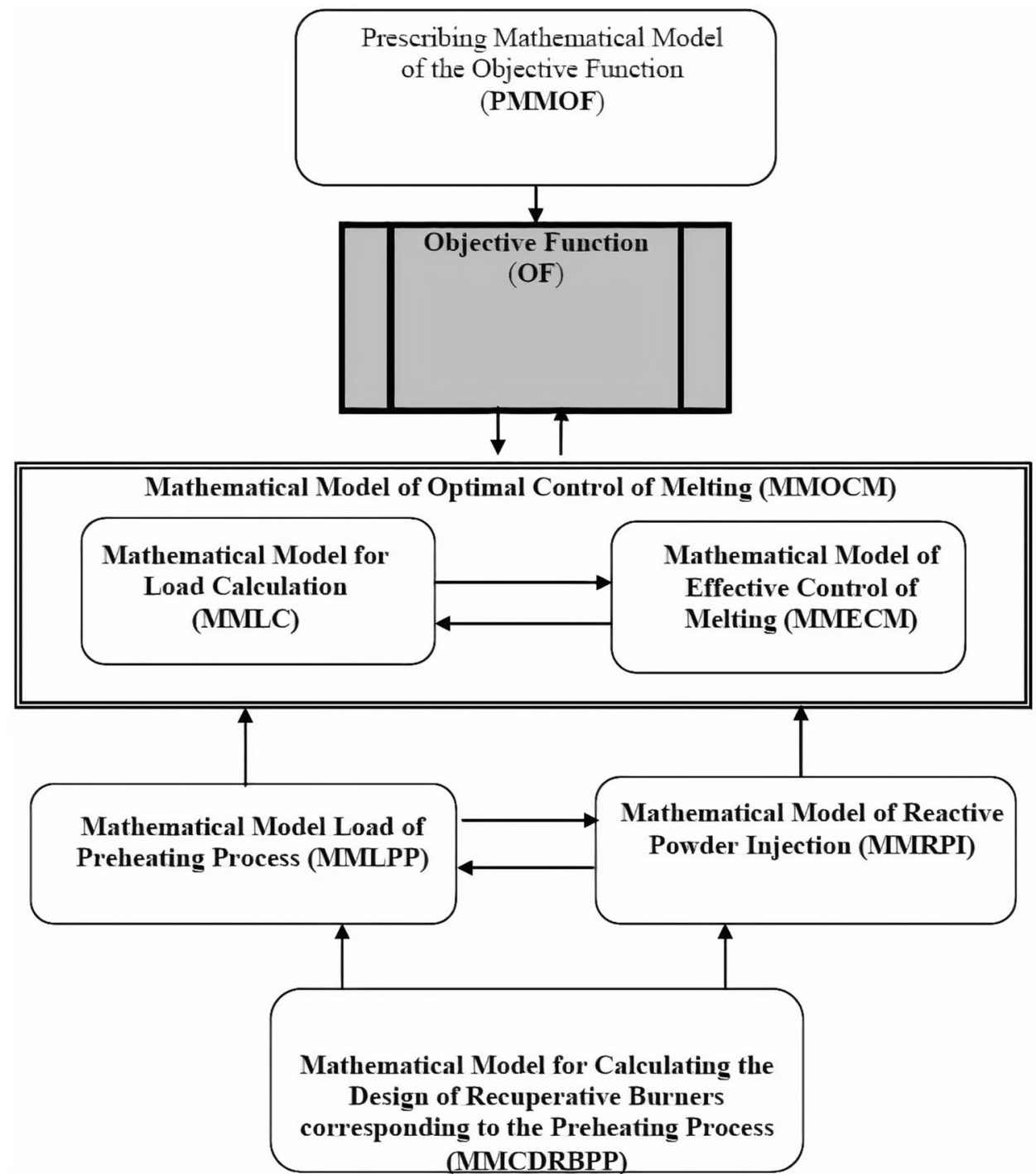

5. Formulating a final solution-depending upon the analysis carried out in previous steps, a final model can be consolidated which fulfils the objective adeptly.

As per M. Costoiu et. al. [34], the mathematical model designed for optimizing the EAF process consists of six subsystems, which are represented by the following models:

- Prescribing Mathematical Model of the Objective Function (PMMOF);

- Mathematical Model for Load Calculation (MMLC.);

- Mathematical Model of Effective Control of Melting (MMECM);

- Mathematical Model Load of Preheating Process (MMLPP.);

- Mathematical Model of Reactive Powder Injection (MMRPI);
- Mathematical Model for Calculating the Design of Recuperative Burners corresponding to the Preheating Process (MMCDRBPP)

The design suggested by M. Costoiu et. al. involves the following stages and algorithms which can be summarized in block diagram :

Thus, the formulated model involved a qualitative and economic analysis of the aforementioned processes. The PMMOF design is focused on the quantification of the objective function (OF) as a qualitative and economic matrix as shown in Fig. 21. The OF is obtained by applying an algorithm involving three vectors namely:

1. Vector T-Technical Parameters Vector $\left(\mathrm{t}_{\mathrm{i}}\right)$.

2. Vector E-Economic Parameters Vector $\left(e_{j}\right)$.

3. Vector $\mathrm{P}$-Shares Vector $\left(\mathrm{p}_{\mathrm{k}}\right)$. 


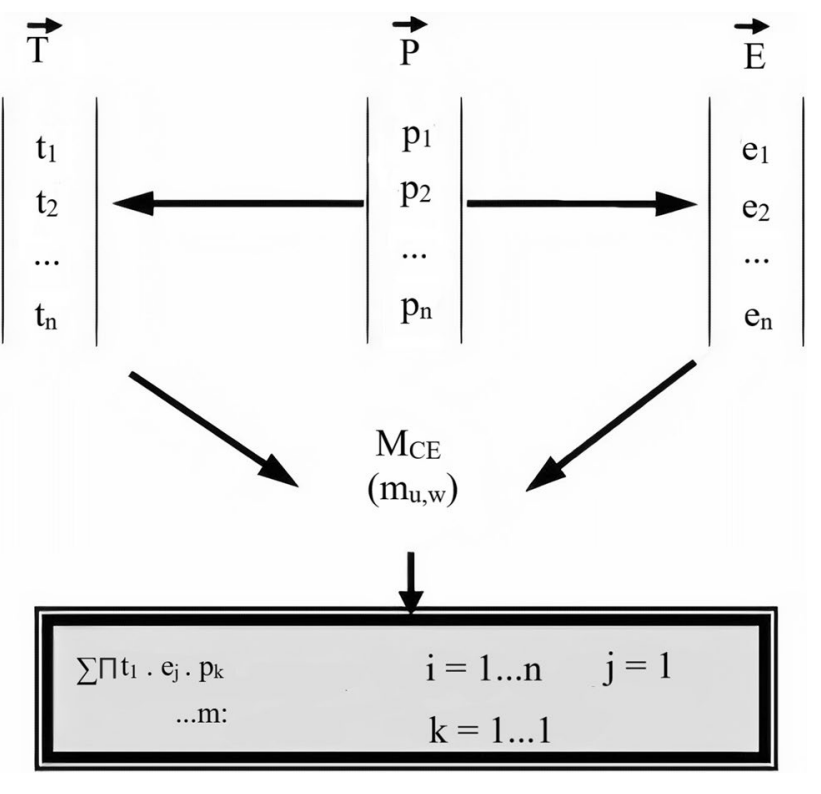

Fig. 21 Quantification of the OF of the modelling system [34]

Vectors $\mathrm{T}$ and $\mathrm{E}$ involve the following technical and economic considerations.

$\mathrm{t}_{1}$-Chemical composition of steel

$t_{2}$-Purity of steel considering the processing gas

$\mathrm{t}_{3}$-Purity of steel considering inclusions

$\mathrm{e}_{1}$-Specific consumptions of raw materials

$\mathrm{e}_{2}$-Specific energy consumption

$\mathrm{e}_{3}$-Melting productivity of EAF

The optimal level $(\mathrm{OL})$ for each of the components in the two vectors can be described as:

For 1 1 - the arithmetic mean of the prescribed limits of variation of the steel composition mark;

For $\mathrm{t} 2$ - the prescribed minimum gas content;

For $\mathrm{t} 3$ - the prescribed minimum content of inclusions;

For e1-specific minimum standards consumption of raw materials;

For e2-the specific prescribed minimum consumption of energy;

For e3 - the normal maximum productivity of the steel elaboration process.

In order to formulate an efficient system that optimizes energy efficiently, employing the DC EAF and the vacuum EAF is advised. The presented model takes into account the correlations of the mathematical models: PMMOF, MMLC, MMECM, and MMLPP which are linked by dual correlations among each other. The objective function of the presented modelling system is the price-quality ratio and the major purpose of the model is to optimize this ratio in order to obtain good quality steel at lower energy costs which involve DC EAF and vacuum EAF usage that alleviate energy consumption while providing enhanced quality steel at the same time [33].

\subsection{Model for minimizing controllable losses and maximizing energy transfer}

In this approach [34], the steelmaking procedure is divided into four steps:

1. The first stage is observed at the beginning of heat and lasts until proper bath temperature is achieved.

2. The second stage continues till a steady state is reached, and this can be detected when the rate of change of slag height approaches zero.

3. The third stage is called as a semi-steady state and lasts until refining is initiated.

4. The fourth stage is known as refining stage and lasts until appropriate composition and bath temperature is achieved.

In this model, the objective function (OF) constitutes three indices:

1. Minimization of energy loss.

2. Maximization of useful energy.

3. Cost minimization.

As per the model, the amount of energy and/or materials gained or lost determines income and expenditures. As a result, incomes are linked to inputs that improve useable energy, such as arc currents and lengths, gas burners, and $\mathrm{O} 2, \mathrm{C}$, and graphite injection, as well as inputs that increase steel mass (greater yield), such as graphite and $C$ injection for the decarburization process. The expenses, on the other hand, are connected to the inputs that cause energy to be lost, such as arc currents and lengths, as well as $\mathrm{O} 2, \mathrm{C}$, and graphite injection, where a portion of the energy is lost by radiation and convection to the walls, roof, gas, and water-cooled panels. Inputs that reduce the mass of steel (lower yield), such as $\mathrm{O} 2$ lancing in the iron oxidation process, affect the prices as well.

End-point restrictions are implemented directly in optimization frameworks, resulting in relatively lengthy prediction horizons and, as a result, significant computational complexity. As a result, for the first three phases of the optimization, the given approach recommends replacing end-point constraints with route constraints. When correctly actuated, path constraints guarantee that circumstances in an EAF at the start of stage four make it easier to meet the required end-point restrictions. Implementing route restrictions on usable EAF power in the second and third stages is therefore comparable to implementing an 


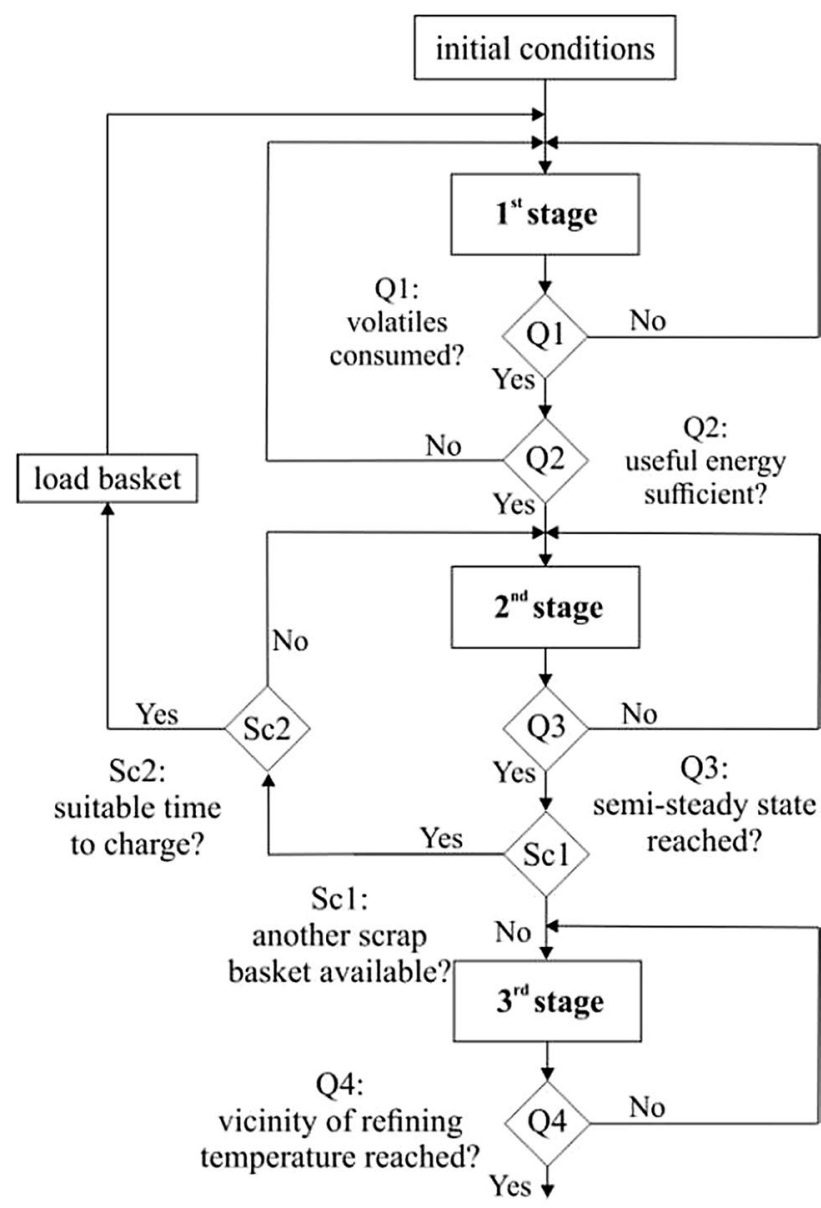

Fig. 22 Conceptual framework of the presented model [36]

end-point constraint on temperature; however, it is considerably easier computationally. The conceptual framework of the model can be visualized in Fig. 22.

The end of each stage is decided by several criteria, such as Q1, Q2, Q3, Q4, Sc1, and Sc2, each of which has the following role:

- Q1 determines if all volatile compounds have been consumed.

- Q2 determines if enough usable energy is given to attain adequate tapping temperature (while also accounting for energy loss during charging), providing that all subsequent steps are correctly activated.

- Q3 determines if the process has achieved a semisteady state, in which the derivative of slag height approaches zero.

- Q4 determines whether the refining temperature has been attained.

- Sc1 checks to see whether another scrap basket is ready to be charged.
Table 4 Comparison between conventional and optimal control

\begin{tabular}{lcc}
\hline Parameter & Conventional control & Optimal control \\
\hline Electrical energy cost & $\$ 5867.0$ & $\$ 5097.6$ \\
Oxygen cost & $\$ 266.6$ & $\$ 312.0$ \\
Oxidized iron cost & $\$ 249.9$ & $\$ 48.6$ \\
Total input costs & $\$ 7091.5$ & $\$ 6159.4$ \\
Useful energy & $38.2 \mathrm{MWh}$ & $38.2 \mathrm{MWh}$ \\
Useful energy costs & $0.186 \$ / \mathrm{MWh}$ & $0.165 \$ / \mathrm{MWh}$ \\
\hline
\end{tabular}

- Sc2 calculates the best time to charge the prepared basket, assuming that the furnace has melted enough steel and the useable furnace power is approaching the minimum allowable value.

Process parameters to be considered in the model include:

1. Slag quality optimization (foaminess): This is required to keep the slag height as near to the length of the arcs as feasible. Energy is lost as a result of both too much and too little slag. Measuring the iron oxide concentration of the slag is one technique to anticipate its foaminess (FeO). Proper oxygen lancing can keep the $\mathrm{FeO}$ between the upper and lower limits in this way.

2. Energy transfer.

3. Arc Length and current.

4. Contribution of carbonaceous materials.

5. Contribution of graphite.

6. Slag quality optimization: appropriate slag basicity, which can be accomplished by adding various slagforming materials, such as dolomite, lime, and brick. Should obtain adequate slag basicity, the quantity of each addition to be applied.

Controlling the specified EAF inputs, such as oxygen lancing, carbon injection, and active power, properly results in enhanced slag properties and height, greater power intensity to the bath, and, as a result, higher EAF efficiency. The results obtained by employing this model are summarized in Table 4 under the heat of $38.2 \mathrm{MWh}$ useful energy.

\section{Conclusion}

A detailed review of factors influencing the energy consumption in the Conarc furnace has been presented along with the technological advancements in various aspects of Conarc steelmaking, focusing on energy optimization and energy management in the entire process. With suggested 
technologies and systems presented, an energy optimization framework is proposed for economically producing steel.

1. Due to emission concerns and regulations set forth by environmental treaties, a specific method of heating the raw materials in the furnace and a specific fuel usage cycle has to be adopted to utilize the energy efficiently during the melting of the raw materials furnace. As a result, fossil fuels must be used to heat and melt the scrap, and an electric arc must be used to heat the bath once the charge has reached a molten state.

2. The type of furnace employed for melting the raw materials plays an essential role in energy consumption during Conarc steelmaking. Either DC or AC furnace is to be used for melting, and each of the two furnace types has its pros and cons. DC furnace is easier to operate mechanically, while AC furnace is easier to maintain electrically. The energy requirements for both the furnaces are only slightly different. Furthermore, the DC furnace offers lesser arc flickering during melting.

3. The process of preheating the charge by the postcombustion reaction regulates the energy consumption during the Conarc process. The energy provided by carbon monoxide preheating can be utilized efficiently by using the oxygen-enhanced combustion (OEC) system, which increases the thermal efficiency of the preheating process by utilizing a high-temperature flue gas and flame. This thermochemical approach is one of several ways to reduce power use by eliminating the energy conversion process from fossil fuels to electricity.

4. The oxygen lancing process in Conarc steelmaking can be made more dynamic by using the jet-box system, which decreases energy consumption and contributes to enhancing the productivity of the Conarc process by reducing the tap-to-tap time, as the system increases the process dynamism significantly.

5. DRI variables like basicity, feed rate, feed size, \% carbon, \% metallization, \% gangue, and atmospheric conditions during melting significantly influence energy consumption. During DRI melting, the atmosphere must be either reducing or neutral, and the DRI feed size must be optimal. To use the input energy efficiently, the power input rate must be equal to the thermal energy requirements for heating and melting the DRI up to the bath temperature. Additionally, the $\%$ metallization must be greater than or equal to $80 \%$, as it influences the energy requirements directly and contributes to cost savings.

6. Energy loss is observed through radiation and is inevitable in the Conarc shells. The energy lost can be utilized efficiently for other processes using the thermophotovoltaic (TPV) system. The TPV system is a high-density conversion method that uses the radiation generated by a heated body to generate electrical energy. Another advantage of employing the TPV system is that it enhances total heat efficiency with the on-time.

As steelmaking requires much energy, the systems mentioned above can be employed to minimize the energy consumption and optimize the entire Conarc process holistically, promoting an economical and environment-friendly practice of industrial steelmaking.

Acknowledgements The author of this paper would like to thank their professors at Visvesvaraya National Institute of Technology for providing the guidance required for writing the research paper. The author is also thankful to Tata Steel BSL for providing a practical experience of the Conarc furnace. This research work was not funded.

\section{Declarations}

Conflict of interest The authors declared that they have no conflict of interest.

Open Access This article is licensed under a Creative Commons Attribution 4.0 International License, which permits use, sharing, adaptation, distribution and reproduction in any medium or format, as long as you give appropriate credit to the original author(s) and the source, provide a link to the Creative Commons licence, and indicate if changes were made. The images or other third party material in this article are included in the article's Creative Commons licence, unless indicated otherwise in a credit line to the material. If material is not included in the article's Creative Commons licence and your intended use is not permitted by statutory regulation or exceeds the permitted use, you will need to obtain permission directly from the copyright holder. To view a copy of this licence, visit http://creativecommons. org/licenses/by/4.0/.

\section{References}

1. Kirschen M, Pfeifer $H$, Wahlers FJ, Nirosta T (2002) Mass and energy balances of stainless steel EAF. In Proc. 7th Europe Electric Steelmaking Conference (Vol. 26, p. 29)

2. Morales RD, Rodríguez-Hernández H, Conejo AN (2001) A mathematical simulator for the EAF steelmaking process using direct reduced iron. ISIJ Int 41(5):426-436

3. Tupkary RH (2017) Modern steelmaking handbook, pp 398-413

4. Kirschen M, Risonarta V, Pfeifer H (2009) Energy efficiency and the influence of gas burners to the energy related carbon dioxide emissions of electric arc furnaces in steel industry. Energy 34(9):1065-1072

5. Thomson MJ, Evenson EJ, Kempe MJ, Goodfellow HD (2000) Control of greenhouse gas emissions from electric arc furnace steelmaking: evaluation methodology with case studies. Ironmak Steelmak 27(4):273-279

6. Madias J (2014) Electric furnace steelmaking. In Treatise on process metallurgy (pp. 271-300). Elsevier. [Cross-Ref]

7. Bowman B (1993) A technical comparison between AC and DC furnaces. Revue de Métallurgie 90(6):809-816 
8. Oh J, Lee E, Noh D (2015) Development of an oxygen-enhanced combustor for scrap preheating in an electric arc furnace. Appl Therm Eng 91:749-758

9. Website address: https://www.ispatguru.com/conarc-processfor-steelmaking

10. Sambasivam R, Lenka SN, Durst F, Bock M, Chandra S, Ajmani SK (2007) A new lance design for BOF steelmaking. Metall Mater Trans B 38(1):45-53

11. Damstedt B, Laux S, Bool LE III, Vetter J (2019) Oxygen lancing methods for industrial processes. Fuel 243:271-276

12. Brehl J, Shver V, Coburn M, Blakemore R, Steel N, Mendrek A, Zawierci H (2001) An improved method of applying chemical energy into the EAF. Air Products and Chemicals, Inc. [Cross-Ref]

13. Mandal T, Maity A, Sinha KK, Chatterjee S, Mukherjeel A (2018) A comparative analysis of various types of EAFs based on flexibility and operational performance. AISTech 2018. [Cross-Ref]

14. Anderson SH (2002) Educated use of DRI/HBI improves EAF energy efficiency, yield, and downstream operating results. In 7th European Electric Steelmaking Conference \& Expo, AIDM, Venice. [Cross-Ref]

15. Göl M, Salor O, Alboyacı B, Mutluer B, Çadırcı I, Ermiş M (2010) A new field-data-based EAF model for power quality studies. IEEE Trans Ind Appl 46(3):1230-1242

16. Trejo E, Martell F, Micheloud O, Teng L, Llamas A, MontesinosCastellanos A (2012) A novel estimation of electrical and cooling losses in electric arc furnaces. Energy 42(1):446-456

17. Saboohi Y, Fathi A (2018) EAF heat recovery from incident radiation on water-cooler panels using a Thermophotovoltaic system: A conceptual study [Cross-Ref]

18. Website address: https://www.ispatguru.com/development-ofthe-technology-of-electric-arc-furnace-steelmaking/

19. Zhang L, Eskin DG, Katgerman L (2011) Influence of ultrasonic melt treatment on the formation of primary intermetallics and related grain refinement in aluminum alloys. J Mater Sci 46(15):5252-5259

20. Zuliani DJ, Scipolo V, Duarte PE, Born C (2011) Increasing productivity and lowering operating costs while reducing GHG emissions in steelmaking. In Metec InsteelCon 2011 Conference Proceedings. Düsseldorf: Steel Institute VDEh (p. 10) [Cross-Ref]
21. Januard F, Bockel-Macal S, Vuillermoz JC, Laurent J, Lebrun C (2006) Dynamic control of fossil fuel injections in EAF through continuous fumes monitoring. Metall Res Tech 103(6):275-280

22. Echterhof $T$ (2021) Review on the use of alternative carbon sources in EAF steelmaking. Metals 11(2):222

23. Badr K, Kirschen M, Cappel J (2011). Chemical energy and bottom stirring systems-cost effective solutions for a better performing EAF. METEC InSteel-Con, pp 7-10 [Cross-Ref]

24. Utlu Z, Paralı U, Gültekin Ç (2018) Applicability of Thermophotovoltaic technologies in the iron and steel sectors. Energy Techn 6(6):1039-1051

25. Jian, H., (2006). Application of JetBox system on $45 \mathrm{t}$ EAF. Research on Iron and Steel, 05 [Cross-Ref]

26. Raghd M, Al-Deen J (2018) Comparison between DC and AC arc furnaces. Unpublished. https://doi.org/10.13140/RG.2.2.18705.12642

27. Shyamal S, Swartz CL (2019) Real-time energy management for electric arc furnace operation. J Process Control 74:50-62

28. TimoshenNo SN, StovpchenNo AP, KostetsNi YV, GubinsNi MV (2018) Energy efficient solutions for EAF steelmaNing. J Achiev Mater Manuf Eng 88(1):18-24

29. Rakhmonov IU, Reymov KM, Najimova AM, Uzakov B, Seytmuratov BT (2019) Analysis and calculation of optimum parameters of electric arc furnace. J Phys Conf Ser 1399(5):055048

30. Fernando Martinez, A. M. I., \& Fernandez, M. G. TECHNOLOGIES FOR EAF ENERGY OPTIMIZATION 2015

31. Ioana A, Semenescu A, Marcu D, Pollifroni M, Březinová M (2015) Some aspects about product management of electric arc furnace elements. Appl Mech Mater 809:1319-1324

32. Costoiu M, loana A, Semenescu A, Marcu D (2016) EAF management optimization. IOP Conf Ser Mater Sci Eng 161(1):012104

33. Matino I, Colla V, Baragiola S (2017) Electric energy consumption and environmental impact in unconventional EAF steelmaking scenarios. Energy Procedia 105:3636-3641

34. Saboohi Y, Fathi A, Škrjanc I, Logar V (2018) Optimization of the electric arc furnace process. IEEE Trans Industr Electron 66(10):8030-8039

Publisher's Note Springer Nature remains neutral with regard to jurisdictional claims in published maps and institutional affiliations. 